\title{
As PRÁticas de letramento na escola e na família no CONTEXTO DA SURDEZ: REFLEXÕES A PARTIR DO DISCURSO DOS PAIS E PROFESSORES
}

\author{
LITERACY PRACTICES WITHIN THE CONTEXT OF DEAFNESS AT SCHOOL AND IN \\ THE FAM ILY: REFLECTIONS FROM PARENTS' AND TEACHERS' DISCOURSES
}

\author{
Simone SCHEMBERG ${ }^{1}$ \\ Ana Cristina GUARINELLO ${ }^{2}$ \\ Ana Paula de Oliveira SANTANA ${ }^{3}$
}

\begin{abstract}
RESUM O: as experiências com situações significativas de leitura e escrita desempenham um papel fundamental na constituição do sujeito enquanto leitor e autor. No caso das crianças surdas, a participação em práticas sociais de escrita é, desde cedo, restrita, deixando-as em desvantagem em relação às expectativas e hipóteses sobre esta modalidade. Considerando ser na família que se inicia o contato com textos escritos e que é função da escola oferecer o ensino e a diversidade da linguagem escrita, o presente artigo objetiva analisar e discutir as práticas de letramento que permeiam os meios familiar e escolar de um grupo de crianças surdas. A pesquisa foi desenvolvida com 12 professores do ensino regular e 12 pais, tendo como foco alunos surdos, que freqüentam no contraturno, o Centro de Atendimento Especializado em Surdez (CAES) em município da região metropolitana de Curitiba. Com os pais foram desenvolvidas entrevistas enfatizando as práticas de leitura no âmbito familiar. Com os professores foram utilizados questionários (questões fechadas e abertas), enfocando aspectos referentes a práticas de leitura e escrita em sala de aula. Os resultados demonstram que as práticas de leitura são restritas no âmbito familiar, o que implica em refletir sobre como a criança surda está sendo inserida no mundo da escrita e constituindo-se (ou não) como sujeito letrado. Da mesma forma, no espaço escolar as práticas de leitura e escrita são constituídas, ainda, em grande parte a partir do uso do livro didático, o que revela a falta de diversidade de gênero textual em sala de aula.
\end{abstract}

PALAVRAS-CHAVE: Educação Especial; surdez; letramento; família; ensino regular.

\begin{abstract}
: meaningful experiences in reading and writing have a major role in constituting subjects who see themselves as readers and authors. Early on, deaf children generally have little participation in social practices related to writing, which puts them at a disadvantage in relation to their expectations and hypotheses about this mode. Considering that children have their first contact with this language modality in the family and that the role of the school is to teach writing in its full diversity, this study aims to analyze and discuss literacy practices encountered at the home and school environments of a group of deaf children. The study was conducted with 12 teachers from regular schools and 12 parents, centering on deaf students who were registered at the Centro de Atendimento Especializado em Surdez (CAES), an in-service program in a neighbor city in the metropolitan area of Curitiba, Paraná. Interviews were conducted with the parents focusing on aspects related to reading practices at home. Questionnaires (with open and closed questions)

\footnotetext{
${ }^{1}$ Mestre em Distúrbios da Comunicação pela Universidade Tuiuti do Paraná. -simoneschemberg @otmail.com

2 Doutora em Lingüística pela UFPR, Docente do Programa do Mestrado e Doutorado em Distúrbios da Comunicação e do Curso de Graduação em Fonoaudiologia da Universidade Tuiuti do Paraná ana.guarinello@utp.br

${ }^{3}$ Doutora em Lingüística pela UNICAMP, docente do Curso de Graduação em Fonoaudiologia e do Mestrado e Doutorado em Distúrbios da Comunicação da Universidade Tuiuti do Paranáana.santana2@utp.br
} 
were used to collect data with the teachers, focusing on written language practices in the classroom. Results show that reading and writing practices are quite limited in the family environment. This raises issues about how deaf children are (or are not) being immersed in the world of writing in order to constitute themselves as literate beings. Likewise, in school environments, reading and writing practices are still mainly conducted using textbooks, revealing a lack of diversity in the kinds of written material that makes its way into the classroom.

KEYWORD S: Special Education; deafness; literacy; family; regular school.

\section{INTRODUÇÃO}

As discussões em torno do processo educacional do sujeito surdo e do seu desempenho escolar, em geral, apontam e analisam as suas dificuldades em relação a práticas de leitura e escrita. Tais discussões topicalizam questões que denotam os obstácul os queo surdo apresenta, sobretudo, com relação àlíngua portuguesa (FERNANDES, 1990; GÓES, 1999; SILVA, 1999). A partir do século $X X I$, pesquisas têm enfatizado questões relativas ao Letramento dos surdos, trazendo discussões que vão além da temática de aquisição da escrita enquanto processo individual, e que levam em conta o papel do outro enquanto mediador, a dial ogicidade como aspecto fundamental no processo de constituição da escrita, a contextual ização como ponto essencial nesse trabalho, a importância da língua de sinais neste processo e, sobretudo, a função social da escrita (BOTELHO, 2002; FERNANDES, 2003, 2006a, 2006b; LODI, 2004; GUARINELLO, 2007).

Trazer para o âmbito da surdez a discussão sobre letramento implica considerar as práticas de leitura e de escrita dos surdos e de seus familiares. Considera-se que são as práticas presentes no cotidiano da criança que Ihe permitirão fazer recortes e estabelecer interpretações que serão por ela usados enquanto sujeito letrado (ROJO, 1998). Sendo assim, é no contexto familiar que a criança, ao ter seus primeiros contatos com a linguagem escrita, estabelece seus primeiros significados. Se desde cedo uma criança convive com materiais de leitura, tais como: livros, jornais e revistas, se ouve histórias e observa as pessoas lendo e escrevendo e manipula lápis, borracha, papel, ao ingressar na escola achará tudo muito natural e lógico, já que será uma continuidade daquilo que já vivenciava em casa (CAGLIARI, 1995).

Por muito tempo acreditou-se (acredita-se) que para escrever a criança (surda) deveria falar, porém é preciso considerar que são as práticas deletramento que irão interferir nesse processo. A lém disso, sabe-se também que a relação entre oralidade/ escrita não é direta (Santana, 2007), não basta assim, falar bem para escrever bem. Segundo Gesueli (1998), as dificuldades apresentadas pelos surdos frenteàs práticas deleitura eescrita não estão rel acionadas ao fato denão ouvirem ou denão dominarem a linguagem oral, mas às condições que lhesão propiciadas pelo meio e pel o grupo social. Algumas pesquisas (GESUELI, 1998; ANTIA, REED, KREIMEYER, 2005; DECHANDT, 2006) têm mostrado que muitos surdos que não desenvolveram a linguagem oral, ou que têm pouco conhecimento sobre a 
mesma, são bem sucedidos em relação à leitura e à escrita. Assim, é importante considerar que, para além dos aspectos relacionados à surdez propriamente dita, a interação familiar é um fator que deve ser ponderado em relação à constituição da leitura e escrita por estes sujeitos.

Se, por um lado, a temática letramento e surdez pode ser considerada ainda recente; por outro, a escrita do surdo, especificamente suas dificuldades com a escrita e a leitura, já vêm sendo descrita pela literatura há algum tempo. Muitos trabalhos que investigam o processo de desenvolvimento da linguagem escrita de alunos surdos incluídos no ensino regular, referem-se à falta de vocabulário como uma das principais dificuldades no processo escolar (BOTELHO, 2002; ANTIA, REED, KREIMEYER, 2005).

Antia, Reed e Kreimeyer (2005) realizaram uma pesquisa com 110 surdos de escolas públicas a fim de investigar seu desempenho frente a um teste de linguagem escrita. Esse teste foi apresentado em duas partes, sendo a primeira composta por questões de múltipla escolha a fim de avaliar o vocabulário, a ortografia e estruturas frasais; e a segunda com a finalidade de avaliar a escrita espontânea dos alunos a partir de figuras.

Essa pesquisa revelou que, de um modo geral, apenas $17 \%$ dos alunos tiveram um desempenho acima da média, 32\% alcançaram a média e $51 \%$ tiveram um desempenho abaixo da média, destes $5 \%$ não tiveram nenhuma produção que pudesse ser considerada, resultando em $0 \%$. Não surpreendentemente, o teste demonstrou que a maior dificuldade dos surdos foi em relação ao vocabulário e à sintaxe. Entretanto, no que diz respeito à produção espontânea, a maior parte dos alunos tiveram um resultado acima da média.

No entanto, ainda que muitas pesquisas tenham apontado a falta de vocabulário e a dificuldade com relação à sintaxe na escrita do surdo (FERNAN DES, 1990; SILVA, 1999; ANTIA, REED, KREIMEYER, 2005), há outras questões que se tornam pertinentes, principal mente no que diz respeito a como 0 processo deleitura eescrita éabordado econseqüentementeconcebido pel o sujeito. Para Botelho (2002) a idéia de um vasto vocabulário está associada à perspectiva de construção do sentido do texto, parecendo que a língua consiste fundamentalmente no léxico, de modo que o contexto em que esse vocabulário está inserido, na maioria das vezes, não é enfatizado.

Partindo de um outro referencial, há autores como Silva (2005), que discutem práticas de letramento no contexto do ensino regular, a partir de depoimentos de pais e professores. N as observações real izadas em sala de aula a autora pôde perceber que as práticas de letramento realizadas com alunos surdos no ensino regular são restritas, quando existem, sendo realizadas com maior ênfase em outros contextos, como em casa ou com professores especializados. Entre as justificativas para esse fato está a de que o professor do ensino comum não se sente preparado para atender às diferenças do aluno surdo e, além disso, não o considera como sua responsabilidade. 
Silva (2005) chama atenção também para a ausência de práticas discursivas com o aluno surdo, de modo que a el e são proporcionadas atividades quase que exclusivamente de cópias, diante das quais não há compreensão por parte do mesmo. Por outro lado, ainda, a prática da cópia gera certo alívio para o professor, pois a partir desta prática tem-se a impressão de que o aluno está compreendendo. A autora retrata a situação de uma aluna surda ao fazer uso da cópia: “(...) o fato de a aluna copiar no caderno o exercício correto dá ao professor a sensação de compreensão do que foi feito e o jogo se completa desta forma: o aluno pode entender que aprender é sinônimo de copiar e o professor tem a ilusão de que ensinou." (p. 135).

Cabe ressal tar que a falta de atividades significativas em sala de aula não se restringe aos surdos, mas em grande parte das práticas escolares também ocorre com ouvintes. O uso corrente de livros didáticos que não refletem o uso significativo da linguagem, acaba referindo a linguagem escrita como algo sem função no ponto de vista do aluno. Sobre esse aspecto Fernandes (2003) destaca que a maior parte dos livros didáticos está carregada da tradição normativa, além de não traduzir o movimento vivo dos falantes, e ressalta a necessidade de setomar as atividades de leitura eescrita com al unos surdos para além do trabal ho com palavras isoladas e frases descontextualizadas, abordando os textos que retratem os diversos gêneros discursivos que se fazem presentes no âmbito social, proporcionando a percepção da função social da linguagem escrita. Sendo assim, ao selecionar um material escrito a ser abordado com o aluno surdo é imprescindível que haja uma reflexão acerca de seu verdadeiro significado e funcional idade frente às atividades de leitura e escrita, recorrendo a textos que estejam presentes socialmente e que sejam percebidos pelo aluno como objeto cultural.

Pan (2006) refere que as práticas de escrita presentes na escola fundam-se num modelo autônomo, diante do qual a escrita é concebida como produto em si e o ato de escrever pressupõe um conjunto de habilidades e capacidades cognitivas por parte da criança que escreve, desconsiderando aspectos culturais, sociais e o lugar ocupado pel o sujeito. Aliado a essas práticas há a concepção equivocada de que a linguagem escrita e a linguagem falada cumprem as mesmas funções, dito de outra forma, uma visão de que a escrita éa transposição das práticas orais impede que se propaguem as diversas funções discursivas da modalidade escrita em sala de aula, restringindo-a a uma abordagem formal da língua. Segundo Trenche e Balieiro (2006) tais práticas não privilegiam uma perspectiva discursiva, na qual o foco não é o ensino da língua em si, mas o desenvolvimento de atividades discursivas que tenham como conseqüência a constituição de significação e a produção de sentidos, distanciando-se das possibilidades de letramento, que dizem respeito, como pontua Soares (2006), ao estado ou condição de uso e prática social da leitura e da escrita, enquanto a alfabetização diz respeito ao domínio das habilidades de leitura e da escrita, de codificação e decodificação, 
Desde cedo, sobretudo em uma sociedade na qual a escrita ocupa um lugar privilegiado, a criança se vê rodeada de materiais portadores desta linguagem: rótulos, embalagens, placas, etc. Além de visualizarem as pessoas a sua volta lendo jornais e revistas (PADDEN, 1990; ZIGOURIS-COE, 2001). Porém, mais do que ter contato é importante que a criança perceba que as palavras têm uma função e é nesse sentido que a escola deve proporcionar meios para que o trabal ho com a escrita seja uma continuidade daquilo que a criança vivencia naturalmente, de modo que seja abordada, assim como na vida diária, em situações significativas de uso.

No que diz respeito às práticas de leitura e escrita desenvolvidas com sujeitos surdos a questão do letramento é ainda mais grave, tendo em vista que tais práticas, ao serem desenvolvidas em sala de aula, em geral, privilegiam aspectos que partem da linguagem oral (BOTELHO, 2002; FERNANDES, 2003; SILVA, 2005). Nesse caso o surdo se encontra em desvantagem, considerando que não há uma participação ativa do mesmo nos contextos lingüísticos. A fal ta deuma língua em comum em sala deaula éum dos grandes obstáculos no processo de constituição da escrita pelo surdo (BOTELHO, 2002).

Fernandes (2006a) ressalta que a maior parte dos encaminhamentos metodológicos na educação de surdos é pensada a partir de recursos e estratégias para a al fabetização de ouvintes, tendo a oral idade como pressuposto. Entretanto, esta é uma realidade inadequada para os surdos, considerando que os mesmos não estabelecem relações grafema-fonema, por ser esta uma experiência auditiva. Diante disso, a autora aponta que a alfabetização não deveria ser o foco na educação dos surdos, mas deveriam ser tomadas como ponto de partida as práticas de letramento.

Ao tomar a oralidade como pressuposto para o ensino da língua o surdo é privado de estabelecer relações que o levem a construir significados em torno da mesma. Como afirma Padden (1990), enquanto a criança ouvinte pode usar os conhecimentos que já possui da linguagem oral na constituição da linguagem escrita, fazendo conexões e apoiada em uma língua, a criança surda precisa explorar os conhecimentos da língua portuguesa (no caso do Brasil) juntamente com o aprendizado da escrita. N este sentido, como refere Gesueli (1998), do ponto de vista de uma proposta bilíngüe, a aquisição da língua portuguesa para o surdo é uma tarefa altamente complexa.

Goulart (2006) destaca que crianças que participam desde cedo de atividades que privilegiam atos de leitura e de escrita, a partir de histórias ou da visualização do contato dos seus familiares com a linguagem escrita, chegam à escola sendo capazes de perceber a função social da mesma. Por outro lado, crianças que têm pouco contato ou poucas oportunidades de participação em eventos de letramento chegam à escola, na maioria das vezes, percebendo a linguagem escrita somente a partir dos textos que lhe são apresentados na escola, que em geral, têm gêneros textuais muito restritos (narrativos, quadrinhas, etc.). 
É sob este aspecto que o adulto, enquanto mediador, desempenha um papel fundamental, pois o envolvimento da criança em atividades cotidianas que lhe propiciem contato com a linguagem escrita terá reflexos positivos no modo que a mesma irá constituir-se como leitora e autora.

No caso das crianças surdas, a participação em atividades discursivas érestrita desde cedo, sobretudo porque em sua maioria são fil has de pais ouvintes, com os quais não há o compartilhamento de uma língua (PADDEN, 1990; BOTELHO, 2002; FERNANDES, 2003; KARN OPP e PEREIRA, 2004). Sendo assim, geral mente as crianças surdas não participam efetivamente de atividades que envolvem o diál ogo ea leitura e a escrita. Dessa forma, ao contrário da criança ouvinte que já chega à escola com uma bagagem lingüística, a criança surda, em geral, não chega com conhecimento suficiente para a atribuição de sentido à escrita, o que ocasiona uma defasagem no que diz respeito à criação de expectativas e hipóteses sobre os significados desta modalidade.

Deacordo com Padden (1990), pesquisas apontam queos surdos filhos de pais surdos demonstram um melhor desempenho nas habilidades de leitura e escrita em relação aos surdos filhos de pais ouvintes, devido ao fato da possibilidade de uma interação linguistica. Dessa forma, é possível perceber que ao significar a linguagem para a criança Ihe são concebidas possibilidades de compreensão e apropriação em torno da constituição da modal idade escrita, pois ao deparar-se com a mesma o sujeito já traz consigo conceitos e significados que foram sendo constituídos a partir das interações.

A lém da interação lingüística, outro fator significativo na constituição do surdo enquanto sujeito leitor são as representações da família em torno da surdez e de suas implicações, bem como o lugar concebido à linguagem escrita na vida do sujeito. Silva (2005), ao buscar investigar as representações da família em torno da surdez e das questões relacionadas ao letramento dos al unos surdos, percebeu que apesar de haver por parte da família uma valorização do diploma escolar como requisito importante na vida futura do surdo, a escrita não ocupa lugar privilegiado no seu dia-a-dia, e não é utilizada em situações significativas: “(...) foi possível perceber, durante as conversas com as mães, pouca ênfase em relação ao uso da escrita fora dos propósitos escolares, por serem essas mães, geralmente, de camadas sociais mais pobres e elas mesmas com muito pouco contato com a escrita." (p. 126).

A autora destaca as representações que as mães entrevistadas fazem da linguagem escrita, compreendendo-a como um código e referindo-se a atividades de cópia como essenciais no cotidiano escolar deseus fil hos. A o mesmo tempo demonstraram uma desvalorização do uso da escrita espontânea pelo filho em situações peculiares do dia-a-dia, pois escrever um bilhete ou em um diário, por exemplo, não significa, para al gumas mães, situações de uso efetivo da linguagem escrita, pois estas, para elas, só podem ser efetivadas em situações que estejam ligadas a tarefas escolares. 
Para grande parte de professores que atuam com alunos surdos, sobretudo no ensino regular e, para a grande parte dos pais, a cópia é o meio pelo qual o aluno/ fil ho demonstra estar seapropriando de determi nado conteúdo escrito. Torna-se, assim, uma simulação de compreensão, tanto para os pais, quanto para o professor, que ao deparar-se com as cópias do filho/ aluno têm a impressão de que está havendo compreensão, da mesma forma que por meio da cópia o filho/ aluno simula estar se apropriando do conteúdo (SILVA, 2005). A prender a escrever, então, no contexto da surdez, seria memorizar a escrita das palavras através da cópia. Essa concepção de escrita ligada apenas à escola é bastante difundida entre a população de modo geral e é decorrente do processo de alfabetização pelo qual passamos, como algo individual.

Nesse sentido é possível refletir acerca da interação e das trocas lingüísticas no âmbito familiar, pois se não há uma percepção de que se o filho surdo está se apropriando ou não das questões relativas ao letramento, também não há um espaço nas interlocuções capaz de permitir a este sujeito demonstrar sua compreensão. A cerca disso, enfatiza-se a importância do posicionamento da família frente às manifestações escritas da criança e de suas hipóteses lingüísticas.

É importante considerar que família e a escola constituem juntas o modo pelo qual a criança irá constituir-se como leitora e autora. Entretanto, em geral, a escola preocupa-se fundamentalmente com a alfabetização, focando-se no desenvolvimento das competências individuais, o que se distancia das práticas desenvolvidas em outras instituições, como a família, o local de trabal ho e outros.

Diante das reflexões até aqui expostas é possível perceber que ao abordar a linguagem escrita é preciso considerá-la como sendo muito mais do que um processo que se constrói a partir de práticas de sala de aula que simplesmente apresentam um sistema de escrita para o aluno. Atribuir significados, função e possibilidades de contextual ização constituem um alicerce para que se possa efetivamente constituir-se como leitor e participar ativamente das práticas de escrita enquanto atividade social. Sendo assim, esta pesquisa objetiva analisar e discutir as práticas de letramento que permeiam os meios familiar e escolar de um grupo de crianças surdas incluídas no ensino regular.

\section{MÉTOdo}

Esta pesquisa foi aprovada pelo comitê de ética sob o protocolo de ${ }^{\circ}$ 076/2006. Foi desenvolvida com pais e professores de um grupo dealunos surdos que se encontram matriculados no ensino regular e que freqüentam, no contraturno, o Centro de Atendimento Especializado em Surdez (CAES). O CAES funciona em um espaço da escola regular em um município da região metropolitana de Curitiba, e tem como pressuposto prestar apoio pedagógico especializado para alunos surdos a partir da proposta de Educação Bilíngüe Língua Brasileira de Sinais (Libras) e língua portuguesa escrita. Fizeram parte da 
pesquisa doze pais ( 3 pais e 9 mães) erespectivamente doze professores deal unos que freqüentam o CAES. Com o grupo de pais foram desenvolvidas entrevistas enfatizando sua visão acerca da educação escolar e do letramento do filho surdo. Com os professores foram utilizados questionários (questões fechadas e abertas), sendo enfocados aspectos referentes à educação escolar do aluno surdo no contexto da inclusão e seu processo de leitura e escrita.

\section{DeSCRIÇÃO DOS SUJEITOS}

\begin{tabular}{|c|c|c|c|c|}
\hline Pai/Mãe & $\begin{array}{c}\text { Último grau de } \\
\text { instrução }\end{array}$ & $\begin{array}{c}\text { Como se comunica } \\
\text { com o } \\
\text { Filho surdo }\end{array}$ & $\begin{array}{c}\text { Fez curso de } \\
\text { LIBRAS }\end{array}$ & $\begin{array}{c}\text { Tem o hábito de } \\
\text { ler (o quê?) }\end{array}$ \\
\hline Pai 1 & $8^{\text {a }}$ série & Oralmente & Não & Sim (jornal, revista) \\
\hline Mãe 2 & $5^{\text {a } \text { série }}$ & Oralmente & Não & Sim (Bíblia) \\
\hline Mãe 3 & $5^{a}$ série & Oralmente & Não & Sim (Bíblia) \\
\hline Mãe 4 & Ens. Médio Completo & Oralmente & Não & Não \\
\hline Mãe 5 & Ens. Médio Completo & Oralmente & Não & Sim (Bíblia) \\
\hline Mãe 6 & $6^{a}$ série & Oralmente & Não & Sim (Bíblia, bulas) \\
\hline Mãe 7 & $\begin{array}{c}\text { Ens. Médio } \\
\text { Incompleto }\end{array}$ & Sinais/Oralmente & Não & Sim (Bíblia) \\
\hline Mãe 8 & $4^{a}$ série & Oralmente & Não & Não \\
\hline Pai 9 & $7^{a}$ série & Oralmente & Não & Sim (revistas) \\
\hline Mãe 10 & Ens. Médio Completo & Oralmente & Sim & Não \\
\hline Pai 11 & $5^{a}$ série & Oralmente & Não & Sim (revistas) \\
\hline Mãe 12 & $2^{a}$ série & Oralmente & Não & Sim (bilhetes) \\
\hline
\end{tabular}

Quadro 1 - Descrição dos pais. 


\begin{tabular}{|c|c|c|c|c|c|}
\hline DESCRIÇÃO & $\begin{array}{c}\text { Série } \\
\text { em que } \\
\text { atua }\end{array}$ & $\begin{array}{c}N^{o} \text { de alunos } \\
\text { em sala }\end{array}$ & $\begin{array}{l}\text { Tempo de } \\
\text { docência }\end{array}$ & $\begin{array}{c}\text { Experiência anterior } \\
\text { com aluno surdo }\end{array}$ & $\begin{array}{c}\text { Formação (área } \\
\text { da Surdez) }\end{array}$ \\
\hline Prof. 1 & $1^{\mathrm{a}}$ & 28 & 10 anos & Não & Não \\
\hline Prof. 2 & $4^{\mathrm{a}}$ & 43 & 17 anos & Não & Sim* \\
\hline Prof. 3 & $1^{\mathrm{a}}$ & 25 & 5 anos & Não & Não \\
\hline Prof. 4 & $4^{a}$ & 28 & 10 anos & Não & Não \\
\hline Prof. 5 & $4^{\mathrm{a}}$ & 35 & 17 anos & Não & $\operatorname{Sim}^{* *}$ \\
\hline Prof. 6 & $1^{\mathrm{a}}$ & 26 & 18 anos & Não & Não \\
\hline Prof. 7 & $5^{\mathrm{a}}$ & 25 & 23 anos & Não & $\operatorname{Sim}^{* *}$ \\
\hline Prof. 8 & $5^{a}$ & 32 & 15 anos & Não & Não \\
\hline Prof. 9 & $4^{\mathrm{a}}$ & 24 & 11 anos & Sim & Sim* \\
\hline Prof. 10 & $5^{\mathrm{a}}$ & 40 & 6 anos & Não & Não \\
\hline Prof. 11 & $5^{\mathrm{a}}$ & 40 & 5 meses & Não & Não \\
\hline \begin{tabular}{|l|} 
Prof. 12 \\
\end{tabular} & $1^{\mathrm{a}}$ & 23 & 10 anos & Não & Não \\
\hline
\end{tabular}

Quadro 2 - Descrição dos professores.

* Libras básico - ** Adicional

\begin{tabular}{|c|c|c|c|c|c|c|c|c|c|c|c|c|}
\hline Criança & $\mathbf{1}$ & $\mathbf{2}$ & $\mathbf{3}$ & $\mathbf{4}$ & $\mathbf{5}$ & $\mathbf{6}$ & $\mathbf{7}$ & $\mathbf{8}$ & $\mathbf{9}$ & $\mathbf{1 0}$ & $\mathbf{1 1}$ & $\mathbf{1 2}$ \\
\hline Id ade & 07 & 13 & 08 & 09 & 12 & 07 & 15 & 11 & 11 & 11 & 11 & 09 \\
\hline Série & $1^{\mathrm{a}}$ & $4^{\mathrm{a}}$ & $1^{\mathrm{a}}$ & $4^{\mathrm{a}}$ & $4^{\mathrm{a}}$ & $1^{\mathrm{a}}$ & $5^{\mathrm{a}}$ & $5^{\mathrm{a}}$ & $4^{\mathrm{a}}$ & $5^{\mathrm{a}}$ & $5^{\mathrm{a}}$ & $1^{\mathrm{a}}$ \\
\hline
\end{tabular}

Quadro 3 - Alguns dados das crianças.

\section{RESULTAdos E discussão}

A fim de investigar como se estabelecem as práticas de leitura e a escrita com o filho/ aluno surdo nos âmbitos familiar e escolar, foi realizada uma análise das perguntas sobre esse tema. Primeiramente, discutiu-se a respeito dos materiais de leitura que circulam no meio familiar, em seguida foi realizada uma discussão acerca de como a linguagem escrita é abordada em sala de aula, a partir de depoimentos dos professores.

No que diz respeito à presença de materiais de leitura em casa 
apontados pelos pais, $100 \%$ apontaram a Bíblia, $75 \%$ relatou que possuem livros em casa, $42 \%$ citou revistas, $33 \%$ jornais e $50 \%$ relatou possuir outros tipos de matérias escritos em casa, tais como, gibis, enciclopédias e panfletos. A penas $50 \%$ dos pais apontaram possuir mais de dois tipos de materiais escritos em casa. Os outros $50 \%$ referiu somente a presenca de livros e Bíblia (25\%), ou somente a Bíblia (25\%)

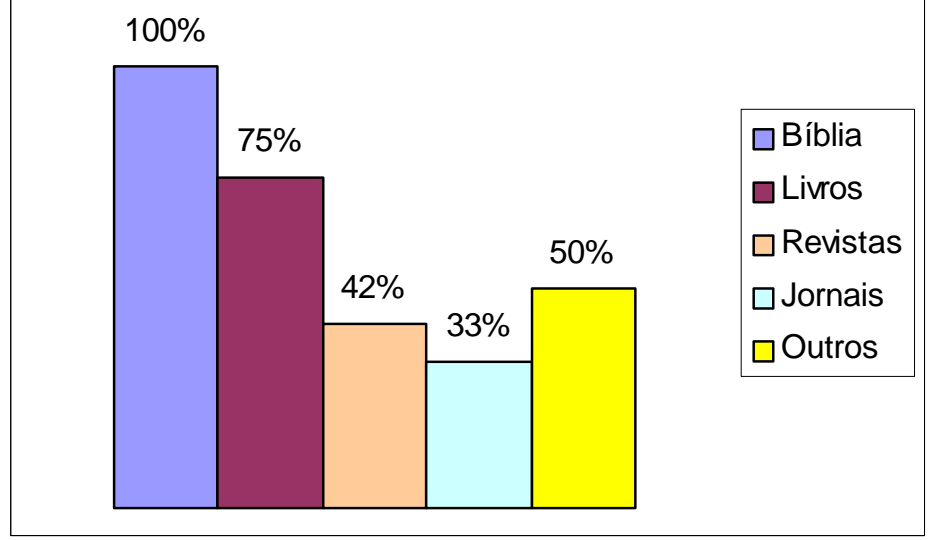

Gráfico 1 - Material de leitura em casa.

FONTE: Pesquisa de campo

Como é possível perceber, a presença de material religioso foi referida por todos os pais entrevistados. Essa ocorrência é muito comum, assim como retratado na pesquisa realizada pelo INAF em 2001 (RIBEIRO, 2003), sobretudo porque o acesso a esse tipo de material é facilmente obtido por amplas camadas da população. Além disso, as práticas de leitura desses materiais são mediadas pela oralidade, sobretudo nas igrejas, o que proporciona, muitas vezes, o reencontro com trechos já memorizados, fazendo com que a leitura da Bíblia possa parecer mais acessível (GALVÃO, 2003). No entanto ao enfocar as práticas de leitura e escrita que circulam socialmente, a Bíblia possui gêneros textuais (parábolas, poesias, provérbios, narrativas) que são pouco utilizados e praticados no contexto de aquisição da escrita. Os mecanismos utilizados pela criança para realizar a interpretação dos textos lidos na Bíblia, um gênero secundário, são complexos (Bakhtin, 1992). Ressalte-se que não foi referido que a Bíblia era uma "Bíblia para crianças". N este caso, as narrativas poderiam ter uma estrutura sintática e semântica que fosse mais significativa e interessante para os leitores, nesse caso, os surdos.

É preciso ressaltar que a presença de materiais de leitura em casa não 
garante práticas de leitura por parte dos pais, pois quando interrogados sobre práticas de leitura, 33\% afirmaram que nunca lê. Dos $67 \%$ que afirmaram ler com freqüência, $41 \%$ referiram somente a leitura da Bíblia, os demais referiram também a leitura de revistas. É possível verificar que na questão relacionada ao tipo de material existente em casa foi feito referência à presença de jornais, enciclopédias, gibis, panfletos, entretanto estes não foram referidos nas práticas de leitura.

Convém indagar sobre qual o lugar da criança surda nessas práticas de leitura pelos pais, ainda que estas sejam restritas. Se as práticas de leitura pel os pais é restrita, como a criança insere-se nesse contexto? Visando verificar se há um compartilhamento de práticas de letramento com a criança surda no contexto familiar, os pais foram questionados se têm o hábito de ler para/ com seu filho surdo. N essa questão $67 \%$ dos pais afirmaram que às vezes lêem para o filho, enquanto outros 33\% afirmaram nunca terem realizado esta prática.

Cabe explicitar que ao serem interrogados (você tem o hábito de ler $\mathrm{com} /$ para seu filho?) em geral, os pais que responderam sim, demonstraram uma reação de surpresa frente ao questionamento, alguns solicitaram que a pergunta fosse refeita, outros ficaram quietos por alguns segundos, como se estivessem pensando em "o quê" responder. Alguns, antecedendo a resposta, expressaram "eh, não, quer dizer, às vezes", "A h, às vezes". Assim, pode-se supor que na visão dos pais, ler com/ para o filho surdo seria uma tarefa impossível ou desnecessária, já que se tem a impressão, muitas vezes, de que por não ouvir, o surdo não compreenderá. N esse caso a leitura não é uma prática social valorizada em casa. Acerca disso Alves e Karnopp (2002) afirmam que é preciso considerar, prioritariamente, que a leitura não deve ser percebida apenas como decodificação ou meramente como um hábito, mas como prática social da linguagem, ligada aos aspectos cultural, social, histórico e ideológico.

Foi possível perceber que justamente entre aqueles que deram uma resposta negativa, dizendo nunca terem lido com/ para o filho (33\%) não houve hesitação, ou seja, a resposta foi curta e objetiva: "N ão". Estes pais, diferentes dos outros, não procuraram dar uma resposta que soasse a 'mais politicamente correta' possível, encarando como ser comum não compartilhar de leituras com o filho.

É fato que, no caso das crianças surdas, a inserção nas práticas cotidianas de letramento torna-se restrita se considerado o entrave lingüístico que se estabelece nas relações diárias, entretanto, o convívio com a linguagem escrita e com cenas de leitura Ihes trará possibilidades para que possam perceber a função da linguagem escrita e que mais tarde, ao deparar-se com o ensino formal da língua portuguesa em âmbito escolar possam estabelecer relações significativas. Não obstante, a presença de práticas de leitura eescrita no cotidiano da criança se refl eteem possibilidades diversas de constituir-secomo sujeito leitor e autor, pois, assim como refere Fernandes (2003): “O sucesso de sua incursão no 
mundo da escrita depende da qualidade e quantidade das experiências de leitura e escrita a que foram submetidas as crianças na infância. “ (p. 139).

Com relação às respostas dos professores, os mesmos apontaram utilizar diferentes tipos de textos em sala, os quais dizem respeito, em ordem de

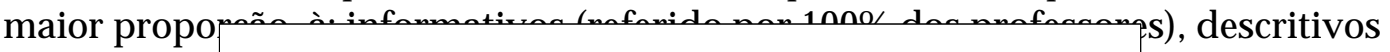
(83\%), narra

$100 \%$

\%).

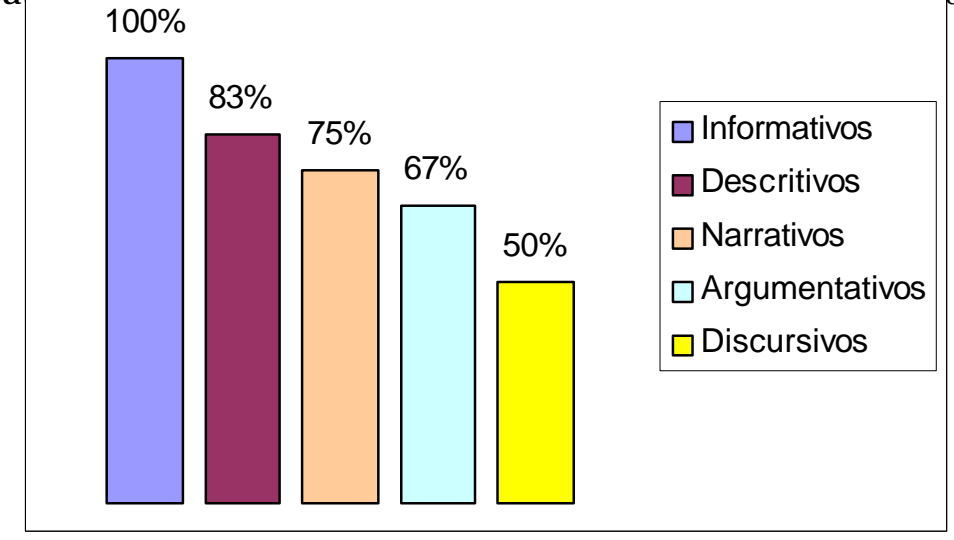

Gráfico 2 - Tipos de textos utilizados em sala de aula.

FONTE: Pesquisa de campo

Com relação aos gêneros textuais, foram apontados pelos professores: quadrinhas (83\%), contos (83\%), reportagens (75\%), bilhetes (67\%), notícias (67\%), receitas $(58 \%)$, cartas $(58 \%)$, piadas $(33 \%)$. Cabe esclarecer que as questões referentes a tipos e gêneros textuais foram constituídas de múltiplas respostas, nas quais as opções já estavam pré-estruturadas, o que de certa forma restringiu as respostas apontadas e ao mesmo tempo pode ter provocado induções. Entretanto uma das opções era aberta e dizia respeito a outros (ou seja, outros tipos e gêneros textuais poderiam ser citados pelo professor), porém esta opção não teve nenhum apontamento. 


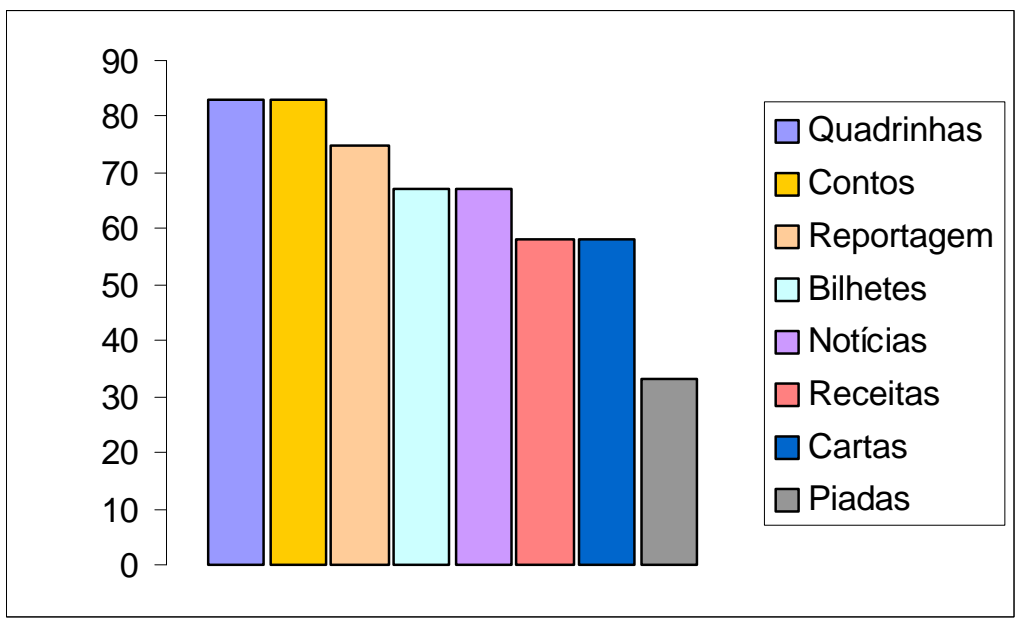

Gráfico 3 - Gêneros textuais utilizados em sala de aula.

Fonte: Pesquisa de campo

Ao considerar esses apontamentos feitos pelos professores, pode-se concluir que o trabal ho com a linguagem escrita se dá de maneira diversificada e a partir de textos que seguramente desempenham uma função social, entretanto, ao analisar suas colocações em relação às fontes de onde retiram os textos abordados em sala de aula, al guns questionamentos podem ser levantados, pois diante da questão: "De que fontes você retira os textos a serem abordados em sala de aula?", $100 \%$ dos professores mencionaram o livro didático em primeira instância. Ainda que al guns professores tenham feito referência a revistas (83\%), jornais (42\%), internet (25\%), gibis (8\%), o livro didático parece ser o grande aliado na seleção dos textos a serem trabalhados em sala.

Ao adotar o livro didático não se contempla outros gêneros em sua plenitude, pois ainda que se aborde, por exemplo, uma reportagem, uma receita, uma carta, se estes são referidos no livro didático, o gênero é o livro didático, considerando ser este um gênero constituído por outros gêneros, assim como o romance (Bakhtin, 1992) e o fato de serem definidos por sua função social (Koch \& Elias, 2007). O livro didático é, assim, um gênero que tem a função de ensino da língua portuguesa. Contemplar o gênero em sua plenitude consistiria em trazer para a sala de aula o jornal, a revista, a bula de remédio e outros, o que incidiria realmente em práticas de letramento.

Não se intenciona aqui confrontar o uso do livro didático, já que o 
mesmo é um material de apoio, que se bem utilizado, pode beneficiar o trabal ho em sala, entretanto, a questão éque, segundo Guarinello, Massi eBerberian (2007), geralmente os livros didáticos utilizados são ineficientes e não permitem a percepção da função do texto, ou da escrita, pela criança. Assim, o texto deixa de ser para o aluno, uma possibilidade de constituir-se enquanto leitor, servindo apenas como instrumento para o ensino da língua.

Outra questão que chama atenção diz respeito à forma como os textos são apresentados aos al unos em sala deaula. Os professores apontaram: no quadro de giz (83\%), em folhas digitadas (100\%) e no livro didático (67\%). É possível perceber que não houve referência ao fato de os professores utilizarem-se do texto a partir de fontes como jornais, bulas de remédios, fonte do texto projetada. Certamente, é difícil, muitas vezes, para o professor dispor de meios para tornar o acesso a diferenciados materiais escritos considerando um contexto no qual o número de alunos em sala de aula é excessivo eos recursos materiais são precários, porém, raramente há uma escola que não disponha de um retroprojetor ou outro meio multimídia que possa subsidiar na exploração de textos.

De fato, pensar acerca de como se aborda a linguagem escrita em sala de aula, vai muito além de ater-se à questão em torno de que fontes são retirados os textos a serem abordados, pois há de se considerar, sobretudo, que o texto constitui-se, conforme Geraldi (1997), num espaço de interlocução e de produção de sentidos em que: "a leitura incide sobre 'o que setem a dizer' porque lendo a palavra do outro, posso descobrir nela outras formas de pensar que, contrapostas às minhas, poderão me levar à construção de novas formas, e assim sucessivamente." (p. 171).

Geraldi pontua claramente que ao trazer um material escrito para a sala de aula o professor deve ponderar o que esse material "tem a dizer" e qual a função do que se aborda, não sendo tomado apenas como um meio de estimular operações mentais, ou ainda, como um pretexto para se abordar determinados conteúdos. Sendo assim, o trabal ho com a linguagem escrita deve ter como base a contextualização, assim como pontua Fernandes (2006a): “Há necessidade de um trabalho contextualizado, no qual sejam focados conteúdos relacionados à prática da produção escrita, ou seja, o conhecimento gramatical e seu efeito retórico deverão ser decorrentes do uso em atividades significativas de escrita." (p. 140).

Ressalta-se a importância de abordar textos significativos, sobretudo, considerando a inclusão do aluno surdo em sala de aula. É preciso, assim, que o professor perceba que enquanto a criança que ouve já vem com al guns conceitos acerca da linguagem escrita, a criança surda terá muito a compreender.

Ainda acerca do trabalho com textos, todos os professores entrevistados afirmaram trabal har com a linguagem escrita partindo de textos inteiros, no entanto, entreesses, $41 \%$ afirmaram também partir de palavras, sílabas 
isol adas ou letras do al fabeto. Ou seja, al guns ainda não conseguiram desvincularse dos resquícios tradicionalistas, nos quais se partia da letra, para a palavra, para a frase e depois para o texto.

Cabe considerar aqui que quando questionados em que concepção de ensino o professor toma como base em sua prática, em geral, os professores se referiram à concepção sócio-histórica, justificando que éesta a concepção adotada nas diretrizes curriculares do município em queatuam. É possível então, relacionar o fato de todos terem apontado o trabal ho com a escrita a partir de textos inteiros, justamente por ser esse um dos pontos abordados em tais diretrizes. Entretanto, volta-se a questão: há por parte dos professores uma verdadeira noção teórica que norteia sua prática ou somente é induzido por políticas educacionais que exigem este ou aquele tipo de abordagens para o trabal ho com a língua? Já que algumas vezes parece haver uma recorrência a práticas que, de certo modo, são contraditórias: diz-se que se segue uma abordagem sócio-histórica e faz-se uma prática baseada em uma abordagem behaviorista.

É o que ocorre também com a presença da cópia e do ditado em sala. A partir dos depoimentos dos professores foi possível verificar que essas práticas ainda persistem, pois ao serem questionados sobre quais atividades utilizam com os alunos para o trabal ho com a leitura e a escrita, ainda que todos os professores entrevistados tenham afirmado trabalhar com propostas de produção textual, foram feitas referências à cópia e ao ditado. Com relação à cópia, percebe-se que esta é uma prática constante, pois $67 \%$ dos professores entrevistados a apontaram como um dos trabal hos abordados com a escrita em sala de aula.

Outro fator a ser considerado é a prática do ditado, referida por $25 \%$ dos professores. É possível dizer que são poucos os professores que se referiram a essa prática, porém, cabe explicitar novamente que os professores participantes dessa pesquisa têm em sala al unos surdos, o que deveria ser levado em conta ao se propor tal "exercício". Se para alunos que ouvem, esta proposta já se traduz muitas vezes num ato mecânico e sem sentido, quanto mais o é para o aluno surdo, que certamente, por não ouvir o que está sendo "ditado", não concluirá a atividade, o que então confirmaria sua suposta dificuldade em relação à linguagem escrita.

Ainda queatividades com ditados possam ser encaminhadas de modo diferente que o tradicional "ditado de palavras", como: a professora ditar um bilhete a ser entregue aos pais, ou o aluno ditar algo para o professor escrever, ou ainda estratégias quetenham significados com o ditado, seconsiderada a presença do aluno surdo em sala de aula, sob qualquer encaminhamento, um ditado seria uma atividade sem sentido e impossível de ser realizada já que envolve "ouvir" e "escrever", uma transposição áudio-gráfica tão somente, incompatível, assim, com o contexto da surdez e das práticas de inclusão.

Embora a maioria dos professores do grupo estudado evidencie o uso 
de atividades descontextualizadas, encontramos também professores, ainda que seja uma minoria, que procuram considerar diferentes encaminhamentos no trabal ho com a leitura e a escrita com o aluno. Encontramos $18 \%$ dos professores que fizeram referência ao trabal ho com resumos, comentários, debates, dramatização, teatro, o que, de certa forma, leva a supor que nestes contextos o trabal ho com a linguagem escrita é levado em consideração sob diferentes estratégias. O uso de diferentes estratégias no trabalho com a linguagem escrita é de suma importância tanto para surdos quanto para ouvintes, pois dessa forma o aluno pode compartilhar os diferentes modos de apropriação.

\section{CONSIDERAÇÕES FINAIS}

Neste trabal ho foi consi derado que as práticas significativas de leitura e escrita são pontos cruciais na constituição de sujeitos. Desta forma, a família e a escola desempenham um papel fundamental. No âmbito familiar se oportunizam os primeiros contatos e a construção de uma relação com a linguagem escrita e a escola constitui-se como um contínuo na promoção de práticas de leitura e escrita.

No contexto da surdez, nosso estudo pode evidenciar que, se por um lado, as práticas de leitura no âmbito familiar restringem-se principalmente à bíblia, por outro, na escola, predomina o livro didático. Deste modo não élevada em conta a diversidade de gêneros que circulam socialmente, o que é de fundamental importância para a constituição do sujeito enquanto leitor.

A partir dos dados analisados foi possível verificar que há uma carência de propostas de situações significativas de práticas de leitura e escrita que considerem realmente o modo como a criança surda constitui-se frente ao letramento, tanto no âmbito familiar como no âmbito escolar. Cabe ainda refletir sobre o fato de que nestes contextos não é contemplado o uso da Língua de Sinais, - que torna a aquisição dos conceitos pela criança surda uma questão agravante, considerando ser esta a língua a partir da qual constitui seus conceitos de modo significativo, o que contribui sobremaneira para sua inserção no mundo da escrita.

Proporcionar um trabalho com a leitura e a escrita em que sejam privilegiadas práticas significativas com a linguagem certamente irá refletir na maneira como o surdo irá se constituir como leitor e autor. Sendo assim, o lugar concedido ao surdo, desde a infância nas experiências com a língua, influencia seu modo de conceber, utilizar e relacionar-se com a linguagem escrita, de modo a constituir-se ou não como sujeito capaz de fazer uso efetivo desta modalidade.

Muito além de discutir apenas as dificuldades do surdo frente à linguagem escrita este trabal ho procurou apresentar questões relacionadas às práticas de letramento nos meios familiar e escolar, considerando serem estes espaços privilegiados na constitui ção dos sujeitos como leitores eautores. A ponta, assim, para uma necessidade de mudança e conscientização (da escola e da 
família) sobre as práticas deleitura e de escrita como significativas para o processo de letramento da criança, seja ela surda ou ouvinte. No caso da criança surda, ressal te-se que, essas práticas sociais deveriam aparecer mediadas pela língua de sinais. Contudo, o que observamos é que na família e na escola permanece o contexto da exclusão lingüística, quer seja da língua de sinais, quer seja da língua na modalidade escrita. Cabendo ao surdo, assim, obter caminhos outros para que o processo de letramento possa realmente se efetivar.

\section{REFERÊNCIAS}

ALVES, A. C. C.; KARN OPP, L. B. O surdo como contador de histórias. In: LODI, A. C. B.; HARRISON , K. M, C.; CAMPOS, S. R.; TESKE, O. (Org.). Letramento eminorias. Porto Alegre: Mediação, 2002. p. 71-75.

ANTIA, S. D.; REED, S.; KREIMEYER, K. H., Written Language of Deaf and Hard-of-hearing students in Public Schools. Journal of D eaf Studies and D eaf E ducations. p. 244-255. Summer, 2005.

BAKHTIN, M. Estética da criação verbal. São Paulo: Martins Fontes, 1992.

BOTELHO, P. Linguagem eletramento na educação dos sur dos - ideologias epráticas pedagógicas. Belo Horizonte: Autêntica, 2002.

CA GLIARI, L. C. A Ifabetização elingüística. 8ed. São Paulo: Scipione, 1995.

DECH ANDT, S. B. A apropriação da escrita por crianças surdas. In: QUADROS, R. M. (Org.). Estu dos Surdos. Petrópolis: A rara Azul, 2006. v. 1, p. 284-322. (SériePesquisas).

FERNANDES, E. Problemas lingüísticos ecognitivos do surdo. Rio de Janeiro: Agir, 1990.

FERN ANDES, S. E ducação bilíngüepara surdos: identidades, diferenças, contradiçõesemistérios. Tese(Doutorado) - UniversidadeFederal do Paraná, Curitiba, 2003.

. Letramento na Educação bilíngüepara surdos. In: BERBERIAN , A .P.; AN GELIS, C. C. M. de, MASSI, G. (Org.). Letramento, referências em saúde eeducação. São Paulo: Plexus, 2006a. p. 117-144.

. Práticas de Letramento na E ducação Bilíngüe para Surdos. Curitiba: SEED, $2006 \mathrm{~b}$.

GALVÃ O, A. M. O. Leitura: al go quesetransmiteentreas gerações? In. RIBEIRO, V. M. (Org.). Letramento no Brasil: reflexões a partir do IN AF 2001. São Paulo: Global , 2003. p.373-378.

GERALDI, J. W. Portos de passagem. 4. ed. São Paulo: Martins Fontes, 1997.

GESUELI,Z. M. A criança surda eo conhecimento construído na inter locução em língua de sinais. TesedeDoutorado. Universidade Estadual de Campinas, Campinas, 1998.

GOES, M. C. R. Linguagem, Surdez eE ducação. 2. ed. São Paulo: Autores A ssociados, 1999.

GOULA RT, C. Letramento emodos deser letrado: discutindo a base teórico-metodológica de um estudo. Revista Brasileira de E ducação, Rio de Janeiro, v. 11, n. 33, p. 450-562, 2006.

GUARIN ELLO, A. C. 0 papel do outro na escrita dos sujeitos surdos. São Paulo: Plexus, 2007.

GUARINELLO, A. C.; MASSI, G.; BERBERIAN, A. P. Surdez eLinguagem Escrita: um estudo 
de caso. Revista Brasileira de Educação Especial. Marília, v. 13, p. 205-218, 2007.

KARN OPP, L. B.; PEREIRA, M. C. C., Concepções de leitura e escrita e educação desurdos. In: LODI, A. C. B.; HARRISSON, K. M. P; CAMPOS, S. R. L. (Org.). Leitura eescrita no contexto da diversidade. Porto Alegre: Mediação, 2004. p. 33-38.

KOCH, I. V; ELIAS, V. M. C. Ler ecompreender os sentidos do texto. São Paulo: Editora Contexto, 2007.

LODI, A.C. B. A leitura como espaço discursivo de constru ção desentidos: oficina com surdos. Tese (Doutorado) - Pontifícia UniversidadeCatólica, São Paulo, 2004.

PADDEN, C. A. Deaf children and literacy. Internacional Bureau of education. Geneva: UNESCO, Switzerland, 1990.

PAN, M. A. G. S. Letramento Escolar eprocessossubjetivos. In: BERBERIAN, A. P.; MORI- de ANGELIS; C. C.; MASSI , G. Letramento- referências em saúdee educação. São Paulo: Plexus, 2006.

RIBEIRO, V. M. (Org.). Letramento no Brasil. São Paulo: Global, 2003.

ROJO, R. H. R. O letramento na ontogênese: uma perspectiva socioconstrurivista. In: ROJO, R. H. R. (Org.). A Ifabetização eletramento: perspectivas lingüísticas. Campinas: Mercado das Letras, 1998. p.121-171.

SANTANA, A. P. Surdez e Linguagem: aspectos e implicações neurolingüísticas. São Paulo: Plexus, 2007.

SILVA, M. P. M. A construção de sentidos na escrita do sujeito surdo. Dissertação (Mestrado) UniversidadeEstadual de Campinas, Campinas, 1999.

SILVA, I. R. A s representações do surdo na escola e na família: entrea (in)viabilização da difer ença e da deficiência. Tese (Doutorado) - UniversidadeEstadual de Campinas, Campinas, 2005.

SOARES, M. Letramento eescolarização. In: RIBEIRO, V. M. (Org.). Letramento no Brasil. Global: São Paulo, 2003, p. 89-114.

SOARES, M. Letramento, um tema em três gêneros. 2. ed. Belo Horizonte: A utêntica, 2006.

TREN CHE, M.C.B.; BA LIEIRO, C.R. Linguagem, escrita, produção de sentidos ea criança surda: questões para a dínica fonoaudiológica. In: BERBERIAN, A.P.; AN GELIS, C. C. M. De; MASSI, G. (Org). Letramento, referências em saú dee educação. São Paulo: Plexus, 2006.

ZIGOURIS-COE, V. Emergent Literacy. FLaRE Document. Florida Literacy and Excellence Center. Orlando, 2001. Disponível em: http://flare.ucf.edu/ Research/ Emergent\%20Literacy.pdf. A cesso em: 18nov. 2008. 